\title{
Identification of Repellent and Insecticidal Constituents of the Essential Oil of Artemisia rupestris L. Aerial Parts against Liposcelis bostrychophila Badonnel
}

\author{
Xin Chao Liu ${ }^{1}$, Yin Ping $\mathrm{Li}^{2}$, He Qin Li ${ }^{1}$, Zhi Wei Deng ${ }^{2}$, Ligang Zhou ${ }^{3}$, Zhi Long Liu ${ }^{1, *}$ and \\ Shu Shan Du ${ }^{4, *}$
}

1 Department of Entomology, China Agricultural University, Haidian District, Beijing 100193, China; E-Mails: xchliu@yeah.net (X.C.L.); hqliaau@163.com (H.Q.L.)

2 Analytical and Testing Center, Beijing Normal University, Haidian District, Beijing 100875, China; E-Mails: xinjiang20041021@163.com (Y.P.L.); dengzw@bnu.edu.cn (Z.W.D.)

3 Department of Plant Pathology, China Agricultural University, Haidian District, Beijing 100193, China; E-Mail: lqzhou@cau.edu.cn

4 State Key Laboratory of Earth Surface Processes and Resource Ecology, Beijing Normal University, Beijing 100875, China

* Authors to whom correspondence should be addressed; E-Mails: zhilongliu@cau.edu.cn (Z.L.L.); dushushan@bnu.edu.cn (S.S.D.); Tel./Fax: +86-10-6273-2800 (Z.L.L.);

Tel./Fax: +86-10-6220-8032 (S.S.D.).

Received: 22 July 2013; in revised form: 29 August 2013 / Accepted: 30 August 2013 /

Published: 3 September 2013

\begin{abstract}
The aim of this research was to determine the chemical composition and insecticidal and repellent activity of the essential oil of Artemisia rupestris L. aerial parts against the booklice Liposcelis bostrychophila Badonnel and isolation of insecticidal and repellent constituents from the essential oil. The essential oil of $A$. rupestris was obtained by hydrodistillation and analyzed by GC-MS. A total of 30 components of the essential oil of $A$. rupestris was identified and the principal compounds in the essential oil were $\alpha$-terpinyl acetate $(37.18 \%)$, spathulenol (10.65\%), $\alpha$-terpineol $(10.09 \%)$, and linalool $(7.56 \%)$, followed by 4-terpineol (3.92\%) and patchoulol (3.05\%). Based on bioactivity-guided fractionation, the four active constituents were isolated from the essential oil and identified as $\alpha$-terpineol, $\alpha$-terpinyl acetate, 4 -terpineol and linalool. The essential oil of $A$. rupestris exhibited contact toxicity against $L$. bostrychophila with $\mathrm{LD}_{50}$ value of $414.48 \mu \mathrm{g} / \mathrm{cm}^{2}$. $\alpha$-Terpinyl acetate $\left(\mathrm{LD}_{50}=92.59 \mu \mathrm{g} / \mathrm{cm}^{2}\right)$ exhibited stronger contact toxicity against booklice than $\alpha$-terpineol $\left(\mathrm{LD}_{50}=140.30 \mu \mathrm{g} / \mathrm{cm}^{2}\right)$, 4-terpineol $\left(\mathrm{LD}_{50}=211.35 \mu \mathrm{g} / \mathrm{cm}^{2}\right)$,
\end{abstract}


and linalool $\left(\mathrm{LD}_{50}=393.16 \mu \mathrm{g} / \mathrm{cm}^{2}\right)$. The essential oil of A. rupestris $\left(\mathrm{LC}_{50}=6.67 \mathrm{mg} / \mathrm{L}\right.$ air $)$ also possessed fumigant toxicity against L. bostrychophila while the four constituents, 4-terpineol, $\alpha$-terpineol, $\alpha$-terpinyl acetate and linalool had $\mathrm{LC}_{50}$ values of $0.34,1.12,1.26$ and $1.96 \mathrm{mg} / \mathrm{L}$ air, respectively. $\alpha$-Terpinol and $\alpha$-terpinyl acetate showed strong repellency against $L$. bostrychophila, while linalool and 4-terpinol exhibited weak repellency. The results indicate that the essential oil of $A$. rupestris aerial parts and its constituent compounds have potential for development into natural insecticides or fumigants as well as repellents for control of insects in stored grains.

Keywords: Liposcelis bostrychophila; Artemisia rupestris; contact toxicity; fumigant toxicity; repellency; essential oil composition

\section{Introduction}

Booklice (Liposcelis bostrychophila Badonnel; Psocoptera: Liposcelididae) have a worldwide distribution infesting domestic premises, raw material stores, manufacturing factories, and historical documents in museums [1]. Booklice do not bite, or transmit disease and are considered as nuisance pests rather than a cause of losses of stored commodities [2]. Booklice were generally regarded as secondary pests, often overlooked due to their small size and the existence of other more damaging post-harvest primary pests [e.g., maize weevils (Sitophilus zeamais Motschulsky), rice weevils (S. oryzae L.) and lesser grain borer (Rhyzopertha dominica Fabricius)] in cereal grains. However, new evidence indicates that psocids are perhaps the most important emerging pests in stored grains and related commodities due to their small size, and resistance to chemicals [1]. Currently, recommended pest control measures in durable stored food products rely heavily on use of synthetic insecticides/fumigants which pose possible health hazards to warm-blooded animals, risk of environmental pollution, development of resistance by insects and pest resurgence [3] These problems have necessitated a search for alternative eco-friendly insect pest control methods. In recent years, global research has focused on the possible use of essential oils, in protection of stored agricultural products $[4,5]$. Investigations in several countries confirm that some plant essential oils not only repel insects, but possess contact and fumigant toxicity against stored product pests as well as exhibiting feeding inhibition or harmful effects on the reproductive system of insects [4-6].

During the screening program for new agrochemicals from Chinese medicinal herbs and wild plants, the essential oil of Artemisia rupestris L. aerial parts was found to possess insecticidal toxicity against booklice (L. bostrychophila). The genus Artemisia belongs to the family Compositae (Asteraceae) and is a large, diverse genus of plants with about 380 species around the World, of which 186 species (82 endemic) are distributed in China [7]. Many Artemisia species are rich in polyacetylenes, flavonoids, terpenoids, and cyanogenic glycosides and are well-known medicinal plants. Rock wormwood (A. rupestris) is a perennial subshrub distributed in dry hills, desert or semi-desert steppes as well as dry river valleys $(1,100-2,900 \mathrm{~m})$ in the Xinjiang Uyghur Autonomous Region of China and also distributed in Afghanistan, Kazakhstan, Kyrgyzstan, Mongolia, Russia, Tajikistan; East and North of Europe [7]. A. rupestris is a well-known traditional Chinese medicinal plant in the 
Xinjiang of China used for detoxification, with antitumor, antibacterial, and antivirus properties, and is used as well for protecting the liver [8]. Several alkaloids, sesquiterpenoids, sesquiterpene lactone glycosides, triterpenoids, and flavonoids have been identified from A. rupestris [9-17]. The chemical composition of the essential oil derived from A. rupestris aerial parts has been determined previously [18-20]. Essential oils of several Chinese Artemisia species were demonstrated to possess insecticidal activity to grain storage insects [21-28]. However, a literature survey shows that there is no report on insecticidal activity of the essential oil derived from A. rupestris aerial parts. Thus, the objective of this study was to investigate the chemical constituents and insecticidal activity of the essential oil of $A$. rupestris aerial parts against the booklice and isolation of active constituent compounds from the essential oil.

\section{Results and Discussion}

\subsection{Essential Oil Chemical Composition}

The yellow essential oil yield of $A$. rupestris aerial parts was $0.21 \%(\mathrm{~V} / \mathrm{W})$ and the density of the concentrated essential oil was determined as $0.88 \mathrm{~g} / \mathrm{mL}$. A total of 30 components of the essential oil of A. rupestris were identified, accounting for $98.01 \%$ of the total oil (Table 1). The principal compounds in the essential oil were $\alpha$-terpinyl acetate $(37.18 \%)$, spathulenol $(10.65 \%)$, $\alpha$-terpineol (10.09\%), and linalool (7.56\%) followed by 4-terpineol (3.92\%) and patchoulol (3.05\%). Monoterpenoids represented 19 of the 30 compounds, corresponding to $72.97 \%$ of the whole oil, while nine of the 30 constituents $(23.86 \%$ of the crude essential oil) were sesquiterpenoids. The chemical composition of the essential oil of $A$. rupestris aerial parts in the present study was different from that reported in previous studies. For example, $\alpha$-terpinyl acetate $(18.68 \%), \beta$-myrcene $(15.95 \%)$, terpinolene $(8.59 \%)$, $\beta$-terpineol $(5.77 \%)$ and alloocimene $(4.43 \%)$ were the previously reported major compounds in the essential oil of $A$. rupestris [18], however, the two main constituents of the essential oil derived from $A$. rupestris were dihydrocarvyl acetate (31.54\%) and 2-hydroxy-3-(1-propenyl group)-1,4-napthoquinone (27.28\%) [20]. The essential oil from European A. rupestris contained hexadecanol (18.1\%), hexadecanoic acid (11.2\%), guaiol $(6.2 \%)$ and $\beta$-elemene $(3.9 \%)$ [19]. In the previous reports, influence of environmental factors on $p$-cymene, $\gamma$-terpinene, linalool and thymol levels in the essential oil of Thymus migricus was evident [29] and monoterpenes and sesquiterpene hydrocarbons in the essential oils of Lychnophora ericoides were strongly related to chemical balance in soils (organic matter, $\mathrm{P}$ and base saturation) [30]. The above findings demonstrated that there are broad differences in the chemical components for A. rupestris. Thus, further studies on plant cultivation and essential oil standardization are necessary because chemical composition of the essential oil of $A$. rupestris varies greatly with the plant population as well as harvest time. 
Table 1. Chemical constituents of the essential oil derived from Artemisia rupestris aerial parts.

\begin{tabular}{|c|c|c|c|}
\hline Peak No. & RI * & Compound & Composition, $\%$ \\
\hline 1 & 967 & Sabinene & 0.06 \\
\hline 2 & 981 & $\beta$-Pinene & 0.19 \\
\hline 3 & 992 & Myrcene & 1.47 \\
\hline 4 & 1018 & $(+)$-4-Carene & 0.19 \\
\hline 5 & 1023 & $\beta$-Cymene & 0.11 \\
\hline 6 & 1030 & D-Limonene & 0.28 \\
\hline 7 & 1032 & 1,8-Cineol & 0.39 \\
\hline 8 & 1067 & cis-Linalool oxide & 0.19 \\
\hline 9 & 1094 & Linalool & 7.56 \\
\hline 10 & 1175 & 4-Terpineol & 3.92 \\
\hline 11 & 1188 & $\alpha$-Terpineol & 10.09 \\
\hline 12 & 1204 & Verbenone & 0.61 \\
\hline 13 & 1227 & Citronellol & 2.23 \\
\hline 14 & 1255 & Geraniol & 2.01 \\
\hline 15 & 1285 & Bornyl acetate & 0.62 \\
\hline 16 & 1340 & Linalyl propionate & 2.62 \\
\hline 17 & 1349 & $\alpha$-Cubebene & 0.69 \\
\hline 18 & 1351 & $\alpha$-Terpinyl acetate & 37.18 \\
\hline 19 & 1355 & Citronellol acetate & 2.14 \\
\hline 20 & 1356 & Eugenol & 1.18 \\
\hline 21 & 1391 & $\beta$-Elemene & 0.85 \\
\hline 22 & 1420 & $\beta$-Caryophyllene & 1.80 \\
\hline 23 & 1453 & Geranyl acetone & 1.11 \\
\hline 24 & 1457 & (Z)- $\beta$-Farnesene & 0.61 \\
\hline 25 & 1494 & $\alpha$-Selinene & 1.07 \\
\hline 26 & 1523 & $\delta$-Cadinene & 1.36 \\
\hline 27 & 1578 & Spathulenol & 10.65 \\
\hline 28 & 1583 & Caryophyllene oxide & 2.09 \\
\hline 29 & 1663 & Patchoulol & 3.05 \\
\hline \multirow[t]{5}{*}{30} & 1672 & Valeranone & 1.59 \\
\hline & & Total identified & 98.01 \\
\hline & & Monoterpenoids & 72.97 \\
\hline & & Sesquiterpenoids & 23.86 \\
\hline & & Others & 1.18 \\
\hline
\end{tabular}

* RI, retention index as determined on a HP-5MS column using the homologous series of $n$-hydrocarbons.

\subsection{Insecticidial Activities}

The essential oil of $A$. rupestris aerial parts exhibited contact toxicity against $L$. bostrychophila with $\mathrm{LD}_{50}$ value of $418.48 \mu \mathrm{g} / \mathrm{cm}^{2}$ (Table 2 ). When compared with the positive control pyrethrum extract $\left(\mathrm{LD}_{50}=18.99 \mu \mathrm{g} / \mathrm{cm}^{2}\right)$, the essential oil demonstrated 22 times less toxicity to L. bostrychophila. Four constituent compounds, $\alpha$-terpinyl acetate, $\alpha$-terpineol, 4-terpineol acetate and linalool exhibited contact toxicity against the booklice, with $\mathrm{LD}_{50}$ values of $92.59,140.30,211.35$ and $393.16 \mu \mathrm{g} / \mathrm{cm}^{2}$, respectively (Table 2). $\alpha$-Terpinyl acetate had almost 4.5 times more toxicity than the crude essential 
oil against the booklice. Moreover, $\alpha$-terpinyl acetate and $\alpha$-terpineol possessed almost four and three times more toxicity than linalool against booklice, respectively. It is suggested that $\alpha$-terpinyl acetate and $\alpha$-terpineol are major contributors to the insecticidal (contact) activity of the essential oil. However, compared with pyrethrum extract (positive control), $\alpha$-terpinyl acetate showed only five times less toxicity against booklice.

Table 2. Contact toxicity and fumigant toxicity of the essential oil of Artemisia rupestris aerial parts and its constituents against Liposcelis bostrychophila.

\begin{tabular}{cccccc}
\hline Toxicity & Treatment & $\begin{array}{c}\mathbf{L D}_{\mathbf{5 0}} \\
\mathbf{L C}_{\mathbf{5 0}}\end{array}$ & $\mathbf{9 5 \%} \mathbf{F L} *$ & Slope \pm SE & $\begin{array}{c}\text { Chi square } \\
\left(\chi^{\mathbf{2}}\right)\end{array}$ \\
\hline Contact & A. rupestris & 418.48 & $389.34-447.09$ & $8.57 \pm 0.83$ & 17.92 \\
Toxicity & Linalool & 393.16 & $368.45-429.53$ & $9.86 \pm 0.91$ & 13.76 \\
$\left(\mu \mathrm{g} / \mathrm{cm}^{2}\right)$ & $\alpha$-Terpineol & 140.30 & $129.67-151.29$ & $5.08 \pm 0.48$ & 18.48 \\
& $\alpha$-Terpinyl acetate & 92.59 & $85.12-100.45$ & $7.29 \pm 0.74$ & 12.88 \\
& 4-Terpineol & 211.35 & $196.27-230.65$ & $8.74 \pm 0.83$ & 15.47 \\
& Pyrethrum extract & 18.99 & $17.56-20.06$ & $7.64 \pm 1.05$ & - \\
Fumigant & A. rupestris & 6.67 & $6.21-6.98$ & $7.03 \pm 0.63$ & 16.24 \\
$(\mathrm{mg} / \mathrm{L}$ air $)$ & Linalool & 1.96 & $1.85-2.12$ & $5.78 \pm 0.56$ & 12.33 \\
& $\alpha$-Terpineol & 1.12 & $1.01-1.21$ & $4.11 \pm 0.34$ & 14.56 \\
& $\alpha-$ Terpinyl acetate & 1.26 & $1.14-1.33$ & $5.49 \pm 0.51$ & 10.16 \\
& 4-Terpineol & 0.34 & $0.31-0.38$ & $4.13 \pm 0.33$ & 12.19 \\
& Dichlorvos & $1.35 \times 10^{-3}$ & $1.25-1.47 \times 10^{-3}$ & $6.87 \pm 0.77$ & - \\
\hline
\end{tabular}

* Fiducial limits.

4-Terpineol $\left(\mathrm{LC}_{50}=0.34 \mathrm{mg} / \mathrm{L}\right.$ air) exhibited stronger fumigant toxicity against L. bostrychophila adults than $\alpha$-terpineol $\left(\mathrm{LC}_{50}=1.12 \mathrm{mg} / \mathrm{L}\right.$ air $), \alpha$-terpinyl acetate $\left(\mathrm{LC}_{50}=1.26 \mathrm{mg} / \mathrm{L}\right.$ air $)$ and linalool $\left(\mathrm{LC}_{50}=1.96 \mathrm{mg} / \mathrm{L}\right.$ air$)$, while the crude essential oil of $A$. rupestris aerial parts showed an $\mathrm{LC}_{50}$ value of $6.67 \mathrm{mg} / \mathrm{L}$ air (Table 2). 4-Terpineol showed almost 20 times stronger fumigant toxicity than the essential oil against the booklice. However, compared with the positive control, dichlorvos $\left(\mathrm{LC}_{50}=1.35 \times 10^{-3} \mathrm{mg} / \mathrm{L}\right.$ air$), \alpha$-terpineol and the crude essential oil exhibited almost 250 times and 4,940 times less toxicity to L. bostrychophila, respectively. Moreover, in the previous studies, the two active constituent compounds, 4-terpineol and $\alpha$-terpineol have been found to possess strong fumigant toxicity against several grain storage insects, such as $S$. granaries L., S. oryzae, S. zeamais, Tribolium castaneum Herbst, T. confusum L., and $R$. dominica [31-38]. $\alpha$-Terpinyl acetate was regarded as active termiticidal compounds of hinoki wood (Chamaecyparis obtusa) [39]. However, there is no report on fumigant and contact toxicity of $\alpha$-terpinyl acetate against grain storage insects after literature survey. Another constituent compound, linalool was also shown to exhibit fumigant toxicity against several insects. e.g., S. zeamais [40], the triatomine bug (Rhodnius prolixus) [41] and houseflies with a $24 \mathrm{~h} \mathrm{LC}_{50}$ value of $13.6 \mathrm{mg} / \mathrm{L}$ air [42]. Moreover, linalool possessed both contact and fumigant toxicity against human head louse (Pediculus humanus capitis) [43] and exhibited a high acaricidal activity by vapor action against mobile stages of Tyrophagus putrescentiae [44]. 4-Terpineol, $\alpha$-terpineol and linalool were found to be a competitive inhibitor of acetyl-cholinesterase (AchE) [45]. The above findings suggest that insecticidal activity especially fumigant activity of the essential oil of $A$. rupestris aerial 
parts and its four constituent compounds against the booklice is quite promising. As currently used fumigants are synthetic insecticides and the most effective fumigants (e.g., phosphine and methyl bromide) are also highly toxic to humans and other non-target organisms, the essential oil of A. rupestris aerial parts and its four constituent compounds show potential to be developed as possible natural fumigants/insecticides for the control of L. bostrychophila.

In traditional Chinese medicine, A. rupestris aerial parts are used for detoxification and for protecting the liver [8]. Moreover, many pharmacological activities of $A$. rupestris were demonstrated such as anti-tumor, antioxidant, antibacterial, and antivirus properties [8]. It thus seems that this medicinal herb is quite safe for human consumption because it has been used as a medicinal herb for hundreds of years. However, no experimental data about the safety of this herb is available so far, so to develop a practical application for the essential oil and the isolated constituents as novel fumigants/insecticides, further research on the safety of the essential oil/compounds to humans is needed. Additional studies on the development of formulations are also necessary to improve the efficacy and stability and to reduce cost.

\subsection{Repellency}

The results of repellency assays for the essential oil of $A$. rupestris aerial parts and isolated constituents against L. bostrychophila are presented in Table 3. Data showed that at tested concentrations, $\alpha$-terpinol and terpinyl acetate showed strong repellency against L. bostrychophila. At the lowest assayed concentration $\left(3.2 \mathrm{~nL} / \mathrm{cm}^{2}\right)$, the two compounds still showed moderate (Class III) repellency ( $52 \%$ and $48 \%$, respectively) against the booklice at $4 \mathrm{~h}$ after exposure (Table 3 ). Linalool and 4-terpinol also exhibited weak repellency against L. bostrychophila. At the highest concentration $\left(13 \mathrm{~nL} / \mathrm{cm}^{2}\right)$, the compounds exhibited only $53 \%$ and $46 \%$ (Class III) repellency against L. bostrychophila at $4 \mathrm{~h}$ after exposure, respectively (Table 3). Compared with the positive control,

Table 3. Percentage repellency (PR) after two exposure times for the essential oil and isolated constituents against Liposcelis bostrychophila *.

\begin{tabular}{|c|c|c|c|c|c|c|}
\hline \multirow{2}{*}{ Treatment } & \multicolumn{3}{|c|}{$2 \mathrm{~h}$} & \multicolumn{3}{|c|}{$4 \mathrm{~h}$} \\
\hline & $13 \mathrm{~nL} / \mathrm{cm}^{2}$ & $6.4 \mathrm{~nL} / \mathrm{cm}^{2}$ & $3.2 \mathrm{~nL} / \mathrm{cm}^{2}$ & $13 \mathrm{~nL} / \mathrm{cm}^{2}$ & $6.4 \mathrm{~nL} / \mathrm{cm}^{2}$ & $3.2 \mathrm{~nL} / \mathrm{cm}^{2}$ \\
\hline DEET & $100 \pm 0 \mathrm{a}$ & $84 \pm 7 a$ & $72 \pm 9 a$ & $94 \pm 2 \mathrm{a}$ & $82 \pm 6 a$ & $64 \pm 5 a$ \\
\hline Oil & $76 \pm 8 c$ & $56 \pm 4 b$ & $41 \pm 6 b$ & $73 \pm 6 c$ & $42 \pm 9 c$ & $29 \pm 7 \mathrm{~cd}$ \\
\hline Linalool & $72 \pm 5 \mathrm{~cd}$ & $42 \pm 9 c$ & $27 \pm 6 c$ & $53 \pm 9 d$ & $31 \pm 6 d$ & $23 \pm 9 d$ \\
\hline$\alpha$-Terpinol & $85 \pm 4 b c$ & $75 \pm 4 a$ & $69 \pm 9 a$ & $84 \pm 6 b$ & $65 \pm 7 b$ & $52 \pm 7 \mathrm{ba}$ \\
\hline 4-Terpinol & $64 \pm 8 d$ & $55 \pm 5 b$ & $40 \pm 5 b$ & $46 \pm 7 d$ & $47 \pm 7 \mathrm{c}$ & $32 \pm 9 c$ \\
\hline Terpinyl acetate & $91 \pm 7 \mathrm{ab}$ & $76 \pm 7 a$ & $62 \pm 7 a$ & $86 \pm 4 b$ & $67 \pm 9 b$ & $48 \pm 9 b$ \\
\hline
\end{tabular}

* means in the same column followed by the same letters do not differ significantly $(P>0.05)$ in ANOVA and Tukey's tests. PR was subjected to an arcsine square-root transformation before ANOVA and Tukey's tests.

DEET and terpinyl acetate exhibited the same level of repellency against L. bostrychophila at $2 \mathrm{~h}$ after exposure and at $4 \mathrm{~h}$ after exposure, DEET and $\alpha$-terpinol had the same level of repellency (Table 3 ). However, the two other constituents, linalool and 4-terpinol showed less repellency against the booklice. Many essential oils and their constituents had been evaluated for repellency against insects [46]. 
However, only few reports on the booklouse [47-49]. In this paper, we report to isolate four insecticidal and repellent constituents from the essential oil of A. rupestris aerial part against the booklice for the first time. These findings suggest that the essential oil of $A$. rupestris aerial parts and the four isolated compounds show potential for development as natural repellents or insecticides for stored product insects.

\section{Experimental}

\subsection{General}

${ }^{1} \mathrm{H}$ and ${ }^{13} \mathrm{C}-\mathrm{NMR}$ spectra were recorded on Bruker ACF300 [300 MHz (1H)] and AMX500 $[500 \mathrm{MHz}(1 \mathrm{H})]$ instruments using $\mathrm{CDCl}_{3}$ as the solvent with TMS as internal standard. EIMS were determined on a ThermoQuest Trace 2000 mass spectrometer at $70 \mathrm{eV}$ (probe). Components of the essential oil of $A$. rupestris aerial parts were separated and identified by gas chromatography-flame ionization detection (GC-FID) and gas chromatography-mass spectrometry (GC-MS) on an Agilent $6890 \mathrm{~N}$ gas chromatograph equipped with a flame ionization detector connected to an Agilent 5973N mass selective detector. The same capillary column (HP-5MS $30 \mathrm{~m} \times 0.25 \mathrm{~mm} \times 0.25 \mu \mathrm{m}$ ) and analysis conditions were used for both GC-FID and GC-MS.

\subsection{Plant Material and Essential Oil Extraction}

The dried aerial parts of A. rupestris $(5 \mathrm{~kg}$ ) were purchased from Anguo Chinese Medicinal Herbs Market (Anguo 071200, Hebei, China). The plant was identified by Dr. Liu, QR (College of Life Sciences, Beijing Normal University, Beijing, China) and a voucher specimen (CMH-Xinjiangyizhihao-Xinjiang-2013-04) was deposited in the museum of Department of Entomology, China Agricultural University. The sample was ground to a powder using a grinding mill (Retsch Muhle, Haan, Germany). The powder was subjected to hydrodistillation using a modified Clevenger-type apparatus for $6 \mathrm{~h}$ and extracted with $n$-hexane. Anhydrous sodium sulphate was used to remove water after extraction. The essential oil was stored in airtight containers in a refrigerator at $4{ }^{\circ} \mathrm{C}$ for subsequent experiments.

\subsection{Insects}

Booklice, L. bostrychophila were obtained from laboratory cultures in the dark in incubators at 28-30 ${ }^{\circ} \mathrm{C}$ and $70 \%-80 \%$ relative humidity and was reared on a 1:1:1 mixture, by mass, of milk powder, active yeast, and flour. All the containers housing insects and the Petri dishes used in experiments were made escape proof with a coating of polytetrafluoroethylene (Fluon ${ }^{\circledR}$, Blades Biological, Edenbridge, UK). Laboratory bioassays were done within one week after adult collections.

\subsection{Gas Chromatography-Mass Spectrometry}

The GC settings were as follows: the initial oven temperature was held at $60{ }^{\circ} \mathrm{C}$ for 1 min and ramped at $10{ }^{\circ} \mathrm{C} \mathrm{min}{ }^{-1}$ to $180{ }^{\circ} \mathrm{C}$ where it was held for $1 \mathrm{~min}$, and then ramped at $20{ }^{\circ} \mathrm{C} \min ^{-1}$ to $280{ }^{\circ} \mathrm{C}$ and held there for $15 \mathrm{~min}$. The injector temperature was maintained at $270^{\circ} \mathrm{C}$. The samples 
( $1 \mu \mathrm{L}$, diluted to $1: 100$ in acetone) were injected, with a split ratio of 1:10. The carrier gas was helium at flow rate of $1.0 \mathrm{~mL} \cdot \mathrm{min}^{-1}$. Spectra were scanned from 20 to $550 \mathrm{~m} / \mathrm{z}$ at $2 \mathrm{scans} \mathrm{s}^{-1}$. Most constituents were identified by gas chromatography by comparison of their retention indices with those of the literature or with those of authentic compounds available in our laboratories. The retention indices were determined in relation to a homologous series of $n$-alkanes $\left(\mathrm{C}_{8}-\mathrm{C}_{24}\right)$ under the same operating conditions. Further identification was made by comparison of their mass spectra with those stored in NIST 05 (Standard Reference Data, Gaithersburg, MD, USA) and Wiley 275 libraries (Wiley, New York, NY, USA) or with mass spectra from the literature [50]. Component relative percentages were calculated based on GC peak areas without using correction factors.

\subsection{Bioassay-Directed Fractionation}

The crude essential oil of $A$. rupestris aerial parts $(20 \mathrm{~mL})$ was chromatographed on a silica gel (Merck 9385, 1,000 g) column ( $85 \mathrm{~mm}$ i.d., $850 \mathrm{~mm}$ length) by gradient elution with a mixture of solvents ( $n$-hexane, $n$-hexane-ethyl acetate). Fractions $(500 \mathrm{~mL})$ were collected and concentrated at $40{ }^{\circ} \mathrm{C}$, and similar fractions according to thin layer chromatography (TLC) profiles were combined to yield 15 fractions. Fractions (3-5, 7-9) that possessed contact toxicity, with similar TLC profiles, were pooled and further purified by preparative silica gel column chromatography (PTLC) until obtain the pure compound for determining structure as linalool (1, $0.6 \mathrm{~g})$, 4-terpineol (2, $0.3 \mathrm{~g})$, $\alpha$-terpineol (3, $0.8 \mathrm{~g})$, and $\alpha$-terpinyl acetate $(4,1.2 \mathrm{~g})$. The structure of the compounds was elucidated based on high-resolution electron impact mass spectrometry and nuclear magnetic resonance.

\subsection{Isolated Constituent Compounds}

Linalool (1, Figure 1). Colorless oil, ${ }^{1} \mathrm{H}-\mathrm{NMR}\left(\mathrm{CDCl}_{3}, 500 \mathrm{MHz}\right) \delta(\mathrm{ppm}): 5.92(1 \mathrm{H}, \mathrm{dd}, J=10.0,10.0 \mathrm{~Hz}$, H-2), 5.22 (1H, d, $J=20.0 \mathrm{~Hz}, \mathrm{H}-1$, trans), $5.12(1 \mathrm{H}, \mathrm{t}, \mathrm{H}-6), 5.06$ (1H, d, $J=10.0 \mathrm{~Hz}, \mathrm{H}-1$, cis $), 2.03$ $\left(2 \mathrm{H}, \mathrm{m}, 5-\mathrm{CH}_{2}\right), 1.83(1 \mathrm{H}, \mathrm{br}, 3-\mathrm{OH}$, which was removed in the deuterium exchange spectrum after adding a drop of deuterated water), $1.68\left(3 \mathrm{H}, \mathrm{s}, 9-\mathrm{CH}_{3}\right), 1.60\left(3 \mathrm{H}, \mathrm{s}, 8-\mathrm{CH}_{3}\right), 1.53\left(2 \mathrm{H}, \mathrm{m}, 4-\mathrm{CH}_{2}\right)$, $1.27\left(3 \mathrm{H}, \mathrm{s}, 10-\mathrm{CH}_{3}\right) .{ }^{13} \mathrm{C}-\mathrm{NMR}\left(\mathrm{CDCl}_{3}, 125 \mathrm{MHz}\right) \delta(\mathrm{ppm}): 145.05(\mathrm{C}-2), 131.87(\mathrm{C}-7), 124.44$ (C-6), 111.65 (C-1), 73.43 (C-3), 41.57 (C-4), 27.83 (C-10), 25.67 (C-8), 22.71 (C-5), 17.66 (C-9). EI-MS m/z (\%): $154\left(\mathrm{M}^{+}, 5\right), 136$ (15), 121 (25), 109 (11), 93 (80), 83 (18), 80 (30), 71 (100), 69 (50), 55 (45), 43 (39), 41(62), 27 (15). The data matched with previous reports [40,51].

4-Terpineol (2, Figure 1). Colorless oil, ${ }^{1} \mathrm{H}-\mathrm{NMR}\left(\mathrm{CDCl}_{3}, 500 \mathrm{MHz}\right) \delta(\mathrm{ppm}): 5.31(1 \mathrm{H}, \mathrm{dd}, J=5.0 \mathrm{~Hz}$, $2.5 \mathrm{~Hz}, \mathrm{H}-2), 2.18(2 \mathrm{H}, \mathrm{dd}, J=15.0 \mathrm{~Hz}, 5.0 \mathrm{~Hz}, \mathrm{H}-3), 1.94(2 \mathrm{H}, \mathrm{dd}, J=15.0 \mathrm{~Hz}, 5.0 \mathrm{~Hz}, \mathrm{H}-6), 1.72$ (3H, m, H-7), 1.66 (1H, m, H-8), 1.58 (2H, m, H-5), 0.96 (3H, d, J = $10.0 \mathrm{~Hz}, \mathrm{H}-9), 0.94$ (3H, d, $J=5.0 \mathrm{~Hz}, \mathrm{H}-10) .{ }^{13} \mathrm{C}-\mathrm{NMR}\left(\mathrm{CDCl}_{3}, 125 \mathrm{MHz}\right) \delta(\mathrm{ppm}): 133.86$ (C-1), 118.45 (C-2), $71.74(\mathrm{C}-4)$, 36.78 (C-8), 34.61 (C-5), 30.80 (C-3), 27.06 (C-6), 23.28 (C-7), 6.85 (C-9); 6.82 (C-10). EI-MS m/z (\%): $154\left(\mathrm{M}^{+}, 15\right), 111(50), 93$ (44), 86 (23), 71 (100), 69 (21), 68 (15), 55 (17), 43 (29), 41(23). The data matched with previous reports $[40,51]$.

$\alpha$-Terpineol (3, Figure 1). Colorless oil, ${ }^{1} \mathrm{H}-\mathrm{NMR}\left(\mathrm{CDCl}_{3}, 500 \mathrm{MHz}\right) \delta(\mathrm{ppm}): 5.38-5.44(1 \mathrm{H}, \mathrm{m}, \mathrm{H}-2)$, $2.11(1 \mathrm{H}, \mathrm{d}, J=8.4 \mathrm{~Hz}, \mathrm{H}-3), 2.01(1 \mathrm{H}, \mathrm{d}, J=5.0 \mathrm{~Hz}, \mathrm{H}-6), 1.89-1.93$ (2H, m, H-5), 1.78-1.88 (2H, 
m, H-3), 1.67 (3H, s, H -7); 1.47-1.57 (3H, m, H-4), 1.22 (3H, s, H-10), 1.20 (3H, s, H-9). ${ }^{13} \mathrm{C}-\mathrm{NMR}$ $\left(\mathrm{CDCl}_{3}, 125 \mathrm{MHz}\right) \delta(\mathrm{ppm}): 118.45$ (C-2), 134.02 (C-1), 45.01 (C-4), 23.98 (C-5), 31.02 (C-6), 23.34 (C-7), 27.46 (C-10), 72.74 (C-8), 26.89 (C-3), 26.29 (C-9). EI-MS m/z (\%):136 (48), 121 (58), 107 (11), 95 (22), 93 (67), 81 (36), 79 (18), 68(27), 59 (100), 55 (16), 43 (32), 41 (20). The data matched with previous reports $[40,51]$.

$\alpha$-Terpinyl acetate (4, Figure 1). Colorless oil, ${ }^{1} \mathrm{H}-\mathrm{NMR}\left(\mathrm{CDCl}_{3}, 500 \mathrm{MHz}\right) \delta(\mathrm{ppm}): 5.40(1 \mathrm{H}$, brs, H-2), 2.06 (1H, s, H-4), 1.99-2.03 (2H, m, H-6), 2.00 (1H, m, H-3b), 1.98 (3H, s, H-12), 1.86 (1H, m, H-3a), 1.81 (1H, m, H-5b), 1.67 (3H, s, H-7), 1.46 (3H, s, H-10), 1.43 (3H, s, H-9), 1.31 (1H, m, $\mathrm{H}-5 \mathrm{a}) .{ }^{13} \mathrm{C}-\mathrm{NMR}\left(\mathrm{CDCl}_{3}, 125 \mathrm{MHz}\right) \delta$ (ppm): 170.78 (C-11), 133.98 (C-1), 120.32 (C-2), 84.86 (C-8), 42.57 (C-4), 30.89 (C-6), 26.38 (C-3), 23.86 (C-5), 23.31 (C-10), 3.35 (C-9), 23.13 (C-12), 22.50 (C-7). EI-MS m/z (\%): 196 [M+, 5], 136 (58), 121 (100), 105 (22), 93 (86), 91 (46), 77 (26), 67 (37), 51 (21). The data matched with previous reports [51,52].

Figure 1. Constituent compounds isolated from the essential oil of Artemisia rupestris aerial parts.

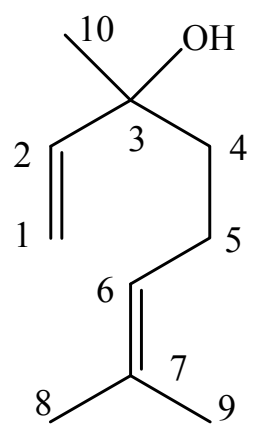

Linalool (1)

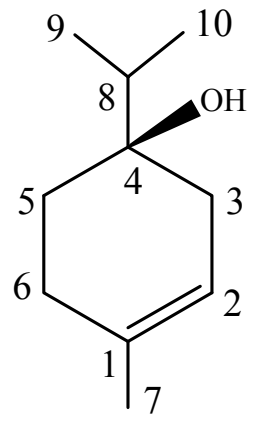

4-Terpineol (2)

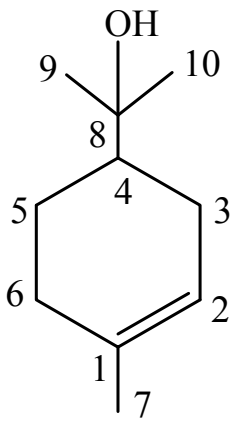

$\alpha$-Terpineol (3)

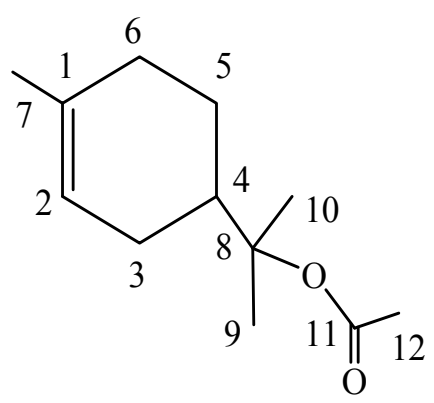

$\alpha$-Terpinyl acetate (4)

\subsection{Contact Toxicity with Treated Filter Paper}

Contact toxicity of the essential oil of $A$. rupestris aerial parts against L. bostrychophila was measured as described by Liu et al. [1]. Range-finding studies were run to determine the appropriate testing concentrations of the essential oil of A. rupestris and pure compounds. The essential oil and compound were diluted in acetone. The filter paper with $3.5 \mathrm{~cm}$ in diameter (Whatman) was treated with $150 \mu \mathrm{L}$ of the solution. Then the filter paper after treated with solid glue (Glue Stick, Jong Ie Nara Co., Ltd. Hong Kong) was placed in a Petri dish (3.5 $\mathrm{cm}$ in diameter) and 10 booklice were put on the filter paper by using a hair brush. The plastic cover with holes was put and all the Petri dishes were kept in incubators at $27-29^{\circ} \mathrm{C}, 70 \%-80 \%$ r.h. for $24 \mathrm{~h}$. Acetone was used as negative control and pyrethrum extract was used as a positive control. Six concentrations $(1.0 \%, 1.2 \%, 1.5 \%, 1.8 \%, 2.2 \%$, and $4.5 \%$ ) and five replicates of each concentration were used in all treatments and controls. Mortality of insects was observed and the observed data were corrected for control mortality using Abbott's formula. The results from all replicates were subjected to probit analysis using the PriProbit Program V1.6.3 to determine $\mathrm{LD}_{50}$ values [53]. Pyrethrum extract (25\% pyrethrine I and pyrethrine II) was purchased from Fluka Chemie (Buchs, Switzerland). 


\subsection{Fumigant Toxicity}

Fumigant toxicity of the essential oil of A. rupestris aerial parts against L. bostrychophila was determined as described by Zhao [54]. Range-finding studies were run to determine the appropriate testing concentrations of the pure compounds and $C$. wenyujin essential oil. A filter paper strip $(3.5 \mathrm{~cm} \times 1.5 \mathrm{~cm})$ treated with $10 \mu \mathrm{L}$ of an appropriate concentration of test essential oil/compound in acetone. The impregnated filter paper was then placed in the bottom cover of glass bottle of $250 \mathrm{~mL}$. The insects, 10 adults in a small glass bottle $(8 \mathrm{~mL})$, were exposed for $24 \mathrm{~h}$. Each concentration had five replicates. Six concentrations $(0.80 \%, 1.0 \%, 1.8 \%, 2.7 \%, 4.0 \%, 6.0 \%)$ were used in all treatments and controls. All the treatments were replicated five times. Acetone was used as negative control and dichlorvos was used as a positive control. The observed mortality data were corrected for control mortality using Abbott's formula. The $\mathrm{LC}_{50}$ values were calculated by using Probit analysis [53]. Positive control, dichlorvos (99.9\%) was purchased from Aladdin Reagent Company (Shanghai, China).

\subsection{Repellency}

The repellency of $A$. rupestris essential oil against $L$. bostrychophila was determined as described by Zhang [48]. Petri dishes (6 $\mathrm{cm}$ in diameter) were used to confine L. bostrychophila during the experiment. The crude essential oil and the isolated compounds were diluted in acetone to three concentrations $\left(13.0,6.4,3.2 \mathrm{~nL} / \mathrm{cm}^{2}\right)$. Filter paper $(6 \mathrm{~cm}$ in diameter) was cut in half and $150 \mu \mathrm{L}$ of each concentration was applied separately to half of the filter paper as uniformly as possible with a micropipette. The other half (control) was treated with $150 \mu \mathrm{L}$ of absolute acetone. Both the treated half and the control half were then air dried to evaporate the solvent completely (10 s). A full disc was carefully remade by attaching the tested half to the negative control half with tape. Care was taken so that the attachment did not prevent free movement of insects from the one half to another, but the distance between the filter-paper halves remained sufficient to prevent seepage of test samples from one half to another. Each remade filter paper after treated with solid glue (Glue Stick, Jong Ie Nara Co., Ltd., location) was placed in a Petri dish with the seam oriented in one of four randomly selected different directions to avoid any insecticidal stimuli affecting the distribution of insects. Twenty insects were released in the center of each filter-paper disc and a cover was placed over the petri dish. Five replicates were used and the experiment was repeated for three times. Counts of the insects present on each strip were made after $2 \mathrm{~h}$ and $4 \mathrm{~h}$. The percent repellency of each volatile oil/compound was then calculated using the formula:

$$
\mathrm{PR}(\%)=[(\mathrm{Nc}-\mathrm{Nt}) /(\mathrm{Nc}+\mathrm{Nt})] \times 100
$$

where Nc was the number of insects present in the negative control half, Nt was the number of insects present in the treated half. Analysis of variance (ANOVA) and Tukey's test were conducted by using SPSS 10 for Windows 98. Percentage was subjected to arcsine square-root transformation before ANOVA and Tukey's tests. The averages were then assigned to different classes (0 to V) (Table 4) [55]. A commercial repellent, DEET ( $N, N$-diethyl-3-methylbenzamide), was purchased from the National Center of Pesticide Standards (Shenyang, China) and used as a positive control. 
Table 4. The scale to be assign repellency of the essential oil of Artemisia rupestris and its constituents.

\begin{tabular}{cccccc}
\hline Class & Percent repellency & Class & Percent repellency & Class & Percent repellency \\
\hline 0 & $>0.01$ to $<0.1$ & II & $20.1-40$ & IV & $60.1-80$ \\
I & $0.1-20$ & III & $40.1-60$ & V & $80.1-100$ \\
\hline
\end{tabular}

\section{Conclusions}

The study indicates that the essential oil of $A$. rupestris aerial parts and its four constituent compounds have potential for development into natural insecticides/fumigants and repellents for control of insects in stored grains.

\section{Acknowledgments}

This project was supported by the Hi-Tech Research and Development of China 2011AA10A202. We thank Liu Q.R. from the College of Life Sciences, Beijing Normal University, Beijing 100875, for the identification of the investigated medicinal herbs.

\section{Conflicts of Interest}

The authors declare no conflict of interest.

\section{References}

1. Liu, Z.L.; Zhao, N.N.; Liu, C.M.; Zhou, L.; Du, S.S. Identification of insecticidal constituents of the essential oil of Curcuma wenyujin rhizomes against Liposcelis bostrychophila Badonnel. Molecules 2012, 17, 12049-12060.

2. Turner, B.D. Psocids as a nuisance problem in the UK. Pestic. Outlook 1998, 9, 27-30.

3. Zettler, J.L.; Arthur, F.H. Chemical control of stored product insects with fumigants and residual treatments. Crop. Prot. 2000, 19, 577-582.

4. Isman, M.B. Botanical insecticides, deterrents, and repellents in modern agriculture and an increasingly regulated world. Ann. Rev. Entomol. 2006, 51, 45-66.

5. Rajendran, S.; Srianjini, V. Plant products as fumigants for stored-product insects control. J. Stored Prod. Res. 2008, 44, 126-135.

6. Regnault-Roger, C.; Vincent, C.; Arnason, J.T. Essential oils in insect control: Low-risk products in a high-stakes world. Annu. Rev. Entomol. 2012, 57, 405-424.

7. Nayak, M.K.; Daglish, G.J.; Byrne, V.S. Effectiveness of spinosad as a grain protectant against resistant beetle and psocid pests of stored grain in Australia. J. Stored Prod. Res. 2005, 41, 455-467.

8. Liu, Y.M. Pharmacography of Uighur (Part I); Xinjiang People's Publishing House: Urumqi, China, 1986.

9. He, F.; Aisa, H.A.; Shakhidoyatov, K.M. Flavones from Artemisia rupestrisa. Chem. Nat. Compds. 2012, 48, 685-686. 
10. He, F.; Nugroho, A.E.; Wong, C.P.; Hirasawa, Y.; Shirota, O.; Morita, H.; Aisa, H.A. Rupestines F-M, new guaipyridine sesquiterpene alkaloids from Artemisia rupestris. Chem. Pharm. Bull. 2012, 60, 213-218.

11. Gu, D.Y.; Yang, Y.; Abdulla, R.; Aisa, H.A. Characterization and identification of chemical compositions in the extract of Artemisia rupestris L. by liquid chromatography coupled to quadrupole time-of-flight tandem mass spectrometry. Rapid Comm. Mass Spectrometry 2012, 26, 83-100.

12. Su, Z.; Wu, H.K.; He, F.; Slukhan, U.; Aisa, H.A. New guaipyridine sesquiterpene alkaloids from Artemisia rupestris L. Helvetica Chimica. Acta 2010, 93, 33-38.

13. Yang, J.B.; Ji, T.F.; Song, W.X.; Wang, A.G.; Su, Y.L. Chemical constituents from herb of Artemisia rupestris. Zhongcaoyao 2008, 39, 1125-1127.

14. Zhao, Y.; Su, Z.; Aisa, H.A. 2-Phenoxychromone flavonoid glycoside from Artemisia rupestris. Chem. Nat. Compds. 2009, 45, 24-26.

15. Aisa, H.A.; Zhao, Y.; He, C.X. A 2-phenoxychromone from Artemisia rupestris. Chem. Nat. Compds. 2006, 42, 16-18.

16. Xu, G.S.; Zhao, W.; Wu, D.; Yu, D.Q.; He, C.H.; Yang, J.J.; Sun, F. The structure and absolute configuration of isorupestonic acid from Artemisia rupestris L. Yaoxue Xuebao 1991, 26, 505-509.

17. Xu, G.S.; Chen, X.Y.; Yu, D.Q. Rupestonic acid, a new sesquiterpene from Artemisia rupestris L. Yaoxue Xuebao 1988, 23, 122-125.

18. Xu, G.S. Chemical constituents of the volatile oil of Artemisia rupestris L. Chin. J. Org. Chem. 1987, 7, 209-212.

19. Bicchi, C.; Frattini, C.; Sacco, T. Essential oils of three Asiatic Artemisia species. Phytochemistry 1985, 24, 2440-2442.

20. Yao, X.Y.; Chao, Q.F.; Chen, Z.D.; Yang, B.Y. Chemical composition and antioxidant activity of the volatile oil from Artemisia rupestris L. Food Sci. Technol. 2012, 37, 213-217.

21. Wang, J.; Zhu, F.; Zhou, X.M.; Niu, C.Y.; Lei, C.L. Repellent and fumigant activity of essential oil from Artemisia vulgaris to Tribolium castaneum (Herbst) (Coleoptera: Tenebrionidae). J. Stored Prod. Res. 2006, 42, 339-347.

22. Yuan, H.B.; Shang, L.N.; Wei, C.Y.; Ren, B.Z. Comparison of constituents and insecticidal activities of essential oil from Artemisia lavandulaefolia by steam distillation and supercritical$\mathrm{CO}_{2}$ fluid extraction. Chem. Res. Chin. Univ. 2010, 26, 888-892.

23. Chu, S.S.; Liu, Q.R.; Liu, Z.L. Insecticidal activity and chemical composition of the essential oil of Artemisia vestita from China. Biochem. Syst. Ecol. 2010, 38, 489-492.

24. Liu, Z.L.; Liu, Q.R.; Chu, S.S.; Jiang, G.H. Insecticidal activity and chemical composition of the essential oils of Artemisia lavandulaefolia and Artemisia sieversiana from China. Chem. Biodiv. 2010, 7, 2040-2045.

25. Liu, Z.L.; Chu, S.S.; Liu, Q.R. Chemical composition and insecticidal activity against Sitophilus.Sitophilus zeamais of the essential oils of Artemisia capillaris and Artemisia mongolica. Molecules 2010, 15, 2600-2608. 
26. Chu, S.S.; Liu, Z.L.; Du, S.S.; Deng, Z.W. Chemical composition and insecticidal activity against Sitophilus zeamais of the essential oils derived from Artemisia giraldii and Artemisia subdigitata. Molecules 2012, 17, 7255-7265.

27. Chu, S.S.; Du, S.S.; Liu, Q.Z.; Liu, Q.R.; Liu, Z.L. Composition and insecticidal activity of the essential oil of Artemisia igniaria flowering aerial parts against Sitophilus zeamais. J. Med. Plant Res. 2012, 6, 3188-3192.

28. Jiang, G.H.; Liu, Q.R.; Chu, S.S.; Liu, Z.L. Chemical composition and insecticidal activity of the essential oil of Artemisia eriopoda against maize weevil, Sitophilus zeamais. Nat. Prod. Commun. 2012, 7, 267-268.

29. Yavari, A.; Nazeri, V.; Sefidkon, F.; Hassani, M.E. Influence of some environmental factors on the essential oil variability of Thymus migricus. Nat. Prod. Commun. 2010, 5, 943-948.

30. Curado, M.A.; Oliveira, C.B.A.; Jesus, J.G.; Santos, S.C.; Seraphin, J.C.; Ferri, P.H. Environmental factors influence on chemical polymorphism of the essential oils of Lychnophora ericoides. Phytochemistry 2006, 67, 2363-2369.

31. Lee, B.H.; Annis, P.C.; Tumaalii, T.; Choi, W.C. Fumigant toxicity of essential oils from the Myrtaceae family and 1, 8-cineole against 3 major stored-grain insects. J. Stored Prod. Res. 2004, $40,553-564$.

32. Kordali, S.; Aslan, I.; Calmasur, O.; Cakir, A. Toxicity of essential oils isolated from three Artemisia species and some of their major components to granary weevil, Sitophilus granarius (L.) (Coleoptera: Curculionidae). Ind. Crops. Prod. 2006, 23, 162-170.

33. Rozman, V.; Kalinovic, I.; Korunic, Z. Toxicity of naturally occurring compounds of Lamiaceae and Lauraceae to three stored-product insects. J. Stored Prod. Res. 2007, 43, 349-355.

34. Abdelgaleil, S.A.M.; Mohamed, M.I.E.; Badawy, M.E.I.; El-Arami, S.A.A. Fumigant and contact toxicities of monoterpenes to Sitophilus oryzae (L.) and Tribolium castaneum (Herbst) and their inhibitory effects on acetylcholinesterase activity. J. Chem. Ecol. 2009, 35, 518-525.

35. Sener, O.; Arslan, M.; Demirel, N.; Uremis, I. Insecticidal effects of some essential oils against the confused flour beetle (Tribolium confusum du Val) (Col.: Tenebrinoidea) in stored wheat. Asian J. Chem. 2009, 21, 3995-4000.

36. Wang, J.L.; Li, Y.; Lei, C.L. Evaluation of monoterpenes for the control of Tribolium castaneum (Herbst) and Sitophilus zeamais Motsch. Nat. Prod. Res. 2009, 23, 1080-1088.

37. Suthisut, D.; Fields, P.G.; Chandrapatya, A. Fumigation toxicity of essential oils from three Thai plants (Zingiberaceae) and their major compounds against Sitophilus zeamais and Tribolium castaneum. J. Stored Prod. Res. 2011, 47, 222-230.

38. Chu, S.S.; Du, S.S.; Liu, Z.L. Fumigant compounds from the essential oil of Chinese Blumea balsamifera leaves against the maize weevil (Sitophilus zeamais). J. Chem. 2013, doi:10.1155/2013/289874.

39. Ohtani, Y.; Hazama, M.; Sameshima, K. Crucial chemical factors of the termiticidal activity of hinoki wood (Chamaecyparis obtusa) III. Contribution of $\alpha$-terpinyl acetate to the termiticidal activity of hinoki wood. J. Japan Wood Res. Soc. 1997, 43, 1022-1029.

40. Wang, C.F.; Yang, K.; Zhang, H.M.; Cao, J.; Fang, R.; Liu, Z.L.; Du, S.S.; Wang, Y.Y.; Deng, Z.W.; Zhou, L. Components and insecticidal activity against the maize weevils of Zanthoxylum schinifolium fruits and leaves. Molecules 2011, 16, 3077-3088. 
41. Sfara, V.; Zerba, E.N.; Alzogaray, R.A. Fumigant insecticidal activity and repellent effect of five essential oils and seven monoterpenes on first-instar nymphs of Rhodnius prolixus. J. Med. Entomol. 2009, 46, 511-515.

42. Palacios, S.M.; Bertoni, A.; Rossi, Y.; Santander, R.; Urzua, A. Efficacy of essential oils from edible plants as insecticides against the house fly, Musca domestica L. Molecules 2009, 14, 1938-1947.

43. Yang, Y.C.; Lee, S.H.; Clark, J.M.; Ahn, Y.J. Ovicidal and adulticidal activities of Origanum majorana essential oil constituents against insecticide-susceptible and pyrethroid/malathionresistant Pediculus humanus capitis (Anoplura: Pediculidae). J. Agric. Food Chem. 2009, 57, 2282-2287.

44. Sanchez-Ramos, I.; Castanera, P. Acaricidal activity of natural monoterpenes on Tyrophagus putrescentiae (Schrank), a mite of stored food. J. Stored Prod. Res. 2001, 37, 93-101.

45. Ryan, F.M.; Byrne, O. Plant-insect coevolution and inhibition of acetylcholinesterase. J. Chem. Ecol. 1988, 14, 1965-1975.

46. Nerio, L.S.; Olivero-Verbel, J.; Stashenko, E. Repellent activity of essential oils: A review. Bioresource Technol. 2010, 101, 372-378.

47. Wang, J.J.; Tsai, J.H.; Ding, W.; Zhao, Z.M.; Li, L.S. Toxic effects of six plant oils alone and in combination with controlled atmosphere on Liposcelis bostrychophila (Psocoptera: Liposcelididae). J. Econ. Entomol. 2001, 94, 1296-1301.

48. Zhang, J.S.; Zhao, N.N.; Liu, Q.Z.; Liu, Z.L.; Du, S.S.; Zhou, L.; Deng, Z.W. Repellent constituents of essential oil of Cymbopogon distans aerial parts against two stored-product insects. J. Agric. Food Chem. 2011, 59, 9910-9915.

49. Liang, Y.; Li, J.L.; Xu, S.; Zhao, N.N.; Zhou, L.; Cheng, J.; Liu, Z.L. Repellent constituents of the essential oil of Epimedium pubescens aerial parts against two grain storage insects. J. Econ. Entomol. 2013, 106, 513-519.

50. Adams, R.P. Identification of Essential Oil Components by Gas Chromatography/Quadrupole Mass Spectroscopy; Allured: Carol Stream, IL, USA, 2007.

51. Bohlmann, F.; Zeisberg, R.; Klein, E. Naturally occurring terpene derivatives. ${ }^{13} \mathrm{CNMR}$ spectra of monoterpenes. Org. Magn. Reson. 1975, 7, 426-432.

52. Liaw, E.T.; Liu, K.J. Synthesis of terpinyl acetate by lipase-catalyzed esterification in supercritical carbon dioxide. Bioresour. Technol. 2010, 101, 3320-3324.

53. Sakuma, M. Probit analysis of preference data. Appl. Entomol. Zool. 1998, 33, 339-347.

54. Zhao, N.N.; Zhou, L.; Liu, Z.L.; Du, S.S.; Deng, Z.W. Evaluation of toxicities of some common spices essential oils from China against Liposcelis bostrychophila. Food Control 2012, 26, 486-490.

55. Liu, Z.L.; Ho, S.H. Bioactivity of the essential oil extracted from Evodia rutaecarpa Hook f. et Thomas against the grain storage insects, Sitophilus zeamais Motsch and Tribolium castaneum (Herbst). J. Stored Prod. Res. 1999, 35, 317-328.

Sample Availability: Samples of the crude extracts and pure compounds are available from the authors.

(C) 2012 by the authors; licensee MDPI, Basel, Switzerland. This article is an open access article distributed under the terms and conditions of the Creative Commons Attribution license (http://creativecommons.org/licenses/by/3.0/). 